\title{
Escola, linguagem e diversidade cultural nos contextos midiáticos ${ }^{1}$
}

Adilson Citelli

Professor livre-docente do Departamento de Comunicações e Artes da ECA/USP

$e$ Chefe do Departamento de Comunicaçoes e Artes.

Pesquisador do CNPq.

E-mail: citelli@uol.com.br

A escola é a instituição na qual se concentra o processo de educação formal. Daí por que durante muito tempo a leitura, entendida como quase sinônimo de alfabetização pela palavra, se confundiu com um espaço específico de aprendizagem: a sala de aula. A linguagem verbal, concebida quase exclusivamente como recurso, veículo, instrumento do bem pensar, foi considerada um dos núcleos mais significativos das dinâmicas escolares, quando não, o único. Ocorre que o acelerado desenvolvimento dos meios de comunicação, desde as formas tradicionais, envolvendo o rádio e a televisão, até as recentes inovações tecnológicas baseadas na informática, na digitalização dos sistemas, nas integrações entre diferentes suportes, forçou não apenas o deslocamento dos lugares produtores de educação, mas passou a requisitar competências leitoras suscitadas pelas linguagens e códigos ancorados em signos icônicos, indiciais, sonoros etc. Compreende-se o motivo de as estratégias educadoras formais, informais e não-formais serem praticadas por instituições distintas e dadas, tradicionalmente, como ocupando faixas irrecorríveis de atuação.

Em nosso tempo, contudo, o modo de produzir, circular e operar o conhecimento e a informação já não respeita os limites impostos por conveniências institucionais. Vale dizer, nem a escola detém o monopólio dos saberes (malgrado possa com eles trabalhar de modo distinto) tampouco é possível ignorar o fato de a polifonia dos signos ter por hábito dançar segundo ritmos e andamentos que não cabem, apenas, na batuta das palavras (conquanto a permanente importância delas).

Essa dupla constatação decorre, em grande medida, dos imperativos advindos dos contextos midiáticos, um compósito de culturas, tecnologias, modos de ser e existir com e no interior de mensagens evidenciadas pelos veículos de comunicação. Tal cenário, A cultura do novo capitalismo, como intitulado por Richard Sennet ${ }^{2}$, vem convidando a escola a encontrar outras estratégias de relação, tanto no que se refere ao problema educativo formal como no atinente às questões envolvendo as sociabilidades, os processos de aprendizagem requisitados pelo conhecimento em rede.

1. Com ligeiras alterações, o que se lerá foi apresentado no Congresso Internacional de Linguagens, promovido em julho de 2006 pela Universidade Regional Integrada (URI) em Erechim, no Rio Grande do Sul.

2. SENNET, Richard. A cultura do novo capitalismo. São Paulo: Record, 2006. 
De toda sorte, é preciso registrar, antes que sobrevenha a tentação de liquidar a escola e o professor, que a instituição educadora formal, com disposição para se ressignificar, acertando o passo com as novas dinâmicas históricas, possui, ainda, papel fundamental a ser cumprido em uma era cantada em prosa e verso como do conhecimento. As mídias são dotadas de força extraordinária, mas as suas práticas de circulação social podem não ultrapassar o registro informativo, do flagrante espetacular, do caleidoscópio da reportagem, da dispersão da internet, do comentário enviesado do articulista. A escola - malgrado os desajustes já apontados - segue temporalidade diferente daquela praticada pelos meios de comunicação e parece continuar sendo o locus mais seguro para se problematizar e sistematizar, dois verbos pouco afeitos ao acelerado ritmo da televisão, do rádio ou do jornal.

\section{OS CONTEXTOS MIDIÁTICOS}

A escola, sobretudo a pública, conquanto marcada pela diversidade cultural - com filhos de operários, camponeses, classe média, desempregados, terceirizados, sem-terra, sem-teto, brancos, negros, amarelos, católicos, judeus, muçulmanos, budistas, protestantes, ateus, migrantes, imigrantes, ou misturas mais ou menos intensas de um ou vários elementos postos anteriormente -, muitas vezes age como se estivesse diante de uma única e mesma planura. Sem vales, desertos, montanhas, rios, árvores, resta a imensidão de uma platônica planície. Daí a turma de $5^{\mathrm{a}}$ ou $8^{\underline{a}}$ séries, o aluno número 22 , o livro didático de alcance nacional a falar para públicos indistintos: o mesmo texto para meninos e meninas do pampa, da caatinga, da costa e dos seringais. Confunde-se o direito à universalização e ao conhecimento compartilhado com as lógicas editoriais e da indústria cultural do livro didático, que respondem, certamente, à otimização dos lucros e à racionalidade dos processos de produção e distribuição próprias do mercado ${ }^{3}$.

A pressão exercida pelos fatores de padronização sobre a diferença na sala de aula encontra-se amplificada nos produtos midiáticos. A despeito de vivermos em uma cultura de fronteiras, ou de entrelugares - aqueles espaços marcados por múltiplas vozes interculturais, conforme lembra Homi Bhabha ${ }^{4}$-, o que se vê ou lê através dos meios de comunicação, sobretudo os tradicionais, é a tendência geral para ofuscar a reflexividade social, ou seja, o exercício crítico voltado a colocar sob suspeição quer a discriminação de raça, credo, orientação sexual,

3. Ver BACCEGA, Maria Aparecida; FREIRE, Denise de Oliveira. A publicidade nos livros didáticos do Ensino Médio. Revista Comunicação \& Educação. São Paulo: CCA-ECA-USP/Paulinas, n. 2, maio/ago. 2007. (N.E.)

4. BHABHA, Homi. O local da cultura. Belo Horizonte: UFMG, 1998. quer a afirmação liminar de padrões de beleza, status econômico, promoção das mitologias contemporâneas, estampadas no cantor pop, no jogador de futebol, na celebridade passageira eleita pelo Big Brother para ser a nova queridinha do Brasil. Ou seja, os componentes ideológicos que contribuem fortemente para promover ou manter as máscaras dos interesses, conceitos, lutas sociais, perspectivas, funcionam constituindo realidades, muitas vezes, apenas referidas às próprias imagens dispostas, por exemplo, pela televisão.

Faz sentido, nesse quadro, a observação de Tomaz Tadeu da Silva e Pablo Gentile: 
Essas novas formas de constituição da identidade pessoal e social partem de uma compreensão muito precisa do papel da chamada cultura de massa. Nessa compreensão, os chamados meios de comunicação não são vistos propriamente como meios de "comunicação" ou como meios de representação da realidade, mas como meios de fabricação da representação e de envolvimento afetivo do espectador e consumidor ${ }^{5}$.

A idéia da fabricação do real - tão enfatizada pelas teorias da linguagem, podendo ser verificada nos procedimentos editoriais, no jogo do espetacular, nos enganos dos simulacros, nas imagens montadas - matiza parte importante da vida cotidiana, toda ela cruzada por símbolos e sinais emitidos a partir das mídias. É imperioso considerar, também, que a escola, ela própria, não se vê livre de promover, através dos discursos didáticos e do vetor pedagógico disciplinado, o falseamento da extensão representacional da realidade, colocando no lugar desta um conjunto de estigmas e estereótipos que contribuem para ofuscar ou subsumir as diferenças, as diversidades culturais.

\section{LEITURA}

A pluralidade de linguagens, colocadas ao nosso alcance pelos diferentes dispositivos comunicacionais, vem forçando a que se reconsidere o conceito de leitura. Em alerta preliminar, Paulo Freire ensina-nos que ler, antes mesmo de representar o domínio de um sistema de codificação baseado, por exemplo, na palavra, implica um ato de reconhecimento do nosso estar no mundo, motivo pelo qual é pelo aparelho perceptivo, pela sensibilidade, que identificamos coisas e situações, compreendendo significados: os olhos que vêem, o corpo tocado pelo vento, os cheiros emanados dos frutos e da terra molhada pela chuva. Essa quase revelação permitida pelo sensorium - porta de entrada no universo dos sentidos - ancora a conhecida assertiva do citado autor da Pedagogia do oprimido: lemos primeiro o mundo e depois a palavra.

Ocorre que os contextos midiáticos foram, progressivamente, não apenas propondo e disseminando a presença de sistemas multissígnicos como, também, ampliando-os, cruzando-os, configurando um quadro de linguagens complexas cuja leitura e compreensão se tornaram importantes para o entendimento das mensagens geradas pela televisão, pelo rádio, pelo jornal etc. Autores como Adilson Citelli ${ }^{6}$ e David Buckingham ${ }^{7}$ vêm insistindo que a escola pode proceder a programas de alfabetização midiática, propugnando que se tornou tarefa da educação formal convidar os alunos a ler e produzir materiais que permitam apreender como as mensagens dos meios de comunicação são constituídas, quais suas implicações e até onde trabalhar com elas pode ajudar na ampliação do senso crítico, na visagem menos ingênua perante os processos comunicativos. Tal chamamento ancora-se no pressuposto de que os conteúdos e as formas midiáticas estão fundamente presentes na escola, a despeito de serem, muitas vezes, esmaecidas, escondidas ou sonegadas: a televisão, a internet, o rádio tornaram-se onipresentes na vida dos estudantes, estando com eles mesmo quando, na sala de aula, nos pátios, não se apresentam fisicamente.
5. SILVA, Tomaz Tadeu da; GENTILE, Pablo. Neoliberalismo, qualidade total e educação. Petrópolis: Vozes, 1994. p. 18

6. CITELLI, Adilson. Comunicação e educação: a linguagem em movimento. São Paulo: Senac, 2000; Outras linguagens na escola. São Paulo Cortez, 2001; Palavras, meios de comunicação e educação. São Paulo: Cortez, 2006.

7. BUCKINGHAM, David. Media education: literacy, learning and contemporary culture (Educação midiática: instrução, aprendizagem e cultura contemporânea). Cambridge Polity, 2003. 
Daí que aprender a ler os meios de comunicação, antes de procedimento tergiversador ou evasivo, é maneira de melhorar o grau de análise e reflexão acerca das várias faces da vida social, dos atos de consumo, das instâncias de cultura. Nesse ponto é que podemos promover a conjunção entre novas formas de ler e compreender franqueadas pelos veículos de comunicação e suas linguagens complexas - no que se inclui a questão da diversidade cultural, tantas vezes sonegada, mascarada, idealizada ou mitificada pelas mídias - e os processos educadores formalizados pela escola.

\section{POR FIM (MAS NÃO POR ÚLTIMO)}

Buscamos mostrar como, em um cenário marcado pelos meios de comunicação, os atos de leitura se fizeram mais complexos, indo além do universo das palavras ou dos tradicionais sistemas de signos.

No interior desse processo, evidenciamos que os andamentos culturais, quase sempre unicentrados, eurocêntricos, matizados pelos discursos dominantes, continuam sendo reatualizados e revisitados tanto na mídia como na escola, numa espécie de luta permanente para eleger determinada narrativa como a única apta para expressar todas as crenças, os valores, modos de ser e existir. Nesse caso, é inegável o esforço para reduzir a complexidade da vida associativa, em suas redes de sociabilidades e imperativos econômicos, trocando a polifonia dos conflitos pela univocidade dos interesses pretensamente recorrentes.

Torna-se claro que ganhar as batalhas pelos espaços discursivos (naquele compósito residual, emergente/dominante, exposto por Raymond Williams em seu materialismo cultural), substanciados em linguagens verbais, icônicas, indiciais, ou no arranjo entre elas, é central para a afirmação ideológica, de (pré) conceitos de grupos, classes, forças de pressão. Daí a importância de considerar os espaços da escola e da leitura como instâncias interlocutivas, mediadas por multilinguagens passíveis de polêmica e debate, mecanismo através do qual, sem temer a mídia tampouco desconhecer o significado e o lugar social da escola, é possível introduzir a questão da diversidade cultural. Talvez se abra, nesse movimento, uma das vertentes para concretizar o desejo expresso por Paulo Freire: o de ver os processos educativos desdobrando a consciência intransitiva em transitiva e daí à consciência transitivo-crítica; passagem fundamental para garantir a existência de uma sociedade plural, baseada em princípios de tolerância, justiça, inclusão e reconhecimento das diferenças ${ }^{8}$.

\section{ARTIGOS NACIONAIS}

8. Educação \& realidade brasileira. São Paulo: Cortez, 2002
Para este número a revista selecionou artigos que, sob diferentes ângulos e temáticas, registram andamentos de pesquisas e reflexões na interface entre comunicação e educação.

Andréa Borges Leão situa o problema da produção literária para o público infantil, enfatizando o papel dos editores no período da República Velha. 
Escola, linguagem e diversidade cultural nos contextos midiáticos • Adilson Citelli

Maria Aparecida Baccega aprofunda a discussão sobre um tema de grande atualidade: a dissolução dos limites entre ficção e realidade nos discursos midiáticos. Tendo como eixo básico a linguagem verbal, a autora estabelece premissas teóricas instigantes para, em seguida, deter-se nos jogos que presidem os vínculos e afastamentos entre os textos que se apresentam ora como marcados pela ficcionalidade, ora como extensões do real.

Aline Maria de Melo Batista mostra alguns resultados do trabalho de doutorado que realiza junto ao programa de pós-graduação em Educação da Universidade Federal da Paraíba, o qual visa indagar como a educação popular se faz à luz da globalização.

Por último, Anna Maria Balogh, tendo como companhia teórica a obra de Genette e Glowinski, amplia a reflexão sobre o conceito de intertextualidade, examinando singularidades da linguagem televisiva.

\section{ARTIGO INTERNACIONAL}

A seção traz o trabalho da profa. dra. Delia Crovi Druetta, titular da Universidade Nacional Autônoma do México (UNAM) e especialista em Comunicação e Educação. $\mathrm{O}$ texto nos revela uma série de mudanças pelas quais a comunicação vem passando, sintetizadas em três grandes eixos: as novas tecnologias da informação e da comunicação; o modelo político-econômico sustentado pelo neoliberalismo; e o paradigma da sociedade da informação e do conhecimento.

\section{GESTÃO DA COMUNICAÇÃO}

Monica Kondziolková realiza uma pesquisa com usuários do Arte na Escola on-line. Apoiada no conceito de consumo midiático de Nestor Garcia Canclini, a autora divulga as experiências culturais, artísticas e sociais do público que acessa o site, para, em seguida, propor um projeto de intervenção que possa melhorar o diálogo com essa ferramenta on-line.

\section{ENTREVISTA}

Um dos nomes mais significativos dos estudos que inter-relacionam comunicação e educação é o de Geneviève Jacquinot-Delaunay, a entrevistada deste número da revista. Criadora dos cursos de graduação e pós-graduação em tecnologias e educação na Universidade Paris VIII, Jacquinot produziu obra de referência sobre as tensões envolvendo a sociedade midiática e a escola. A entrevista foi realizada pela profa. dra. Rosa Maria Cardoso Dalla Costa, da Universidade Federal do Paraná, também uma estudiosa no campo da comunicação e educação. 
comunicação \& educação • Ano XII • Número 3 • set/dez 2007

\section{CRÍTICA}

A partir do conceito de rizoma, formulado por Deleuze e Guatari, João Anzanello Carrascoza mostra como a telenovela mexicana Rebelde opera esquemas discursivos conservadores, ancorados em estratégias de marketing, que alcançam importantes segmentos da população. $\mathrm{O}$ texto considera tal procedimento mercadológico preso a modelos dominantes, dentre os quais a publicidade.

\section{DEPOIMENTO}

A editora executiva da revista, Consuelo Ivo, colheu o depoimento de um dos mais importantes pianistas brasileiros: Amilton Godoy. Membro do lendário Zimbo Trio, Amilton relata momentos centrais do nosso movimento musical, incluindo o histórico show O fino da bossa, realizado em 1964. Os integrantes do Zimbo Trio criaram, em 1973, o Centro Livre de Aprendizagem Musical (CLAM), experiência educadora responsável pela formação de gerações de grandes músicos.

\section{EXPERIÊNCIA}

Cláudia Lago e Izabel Leão tratam do projeto envolvendo a revista Viração, publicação que visa iniciar os jovens nas práticas jornalísticas. A experiência da Viração é posta na perspectiva dos projetos sociais, que permitem, ao mesmo tempo, profícua discussão sobre os processos comunicacionais e uma inserção nos debates sobre cidadania e movimentos sociais.

\section{POESIA}

Adilson Citelli seleciona e comenta três textos do seminal poeta João Cabral de Melo Neto: A educação pela pedra, Rios sem discurso e Ademir da Guia. Os dois primeiros são produções fundamentais na trajetória do pernambucano, e o último, uma original homenagem ao craque apelidado por Décio Pignatari de Admirável da Guia.

\section{SERVIÇOS}

Nesta seção arrolam-se duas publicações: Educação e pesquisa, da Faculdade de Educação da USP, e Leitura: Teoria \& prática, da Associação de Leitura do Brasil (ABL).

\section{VIDEOGRAFIA}

Maria Ignês Carlos Magno dá seqüência ao conjunto de filmes disponibilizados aos leitores da Comunicação \& Educação, que desejam trabalhar com o cinema 
Escola, linguagem e diversidade cultural nos contextos midiáticos • Adilson Citelli

em sala de aula. Neste número, foram escolhidos Hotel Ruanda e outros filmes e documentários sobre a África, que permitem discutir não apenas questões referentes ao continente africano, mas também qual o papel da comunicação nos contextos marcados pela guerra.

\section{BOLETIM BIBLIOGRÁFICO}

A bibliografia sobre telenovela presta homenagem à profa. dra. Maria Lourdes Motter (Lourdinha), que faleceu em 10 de maio de 2007. Durante doze anos ela foi a responsável por esta seção, contribuindo com a divulgação de obras voltadas à teledramaturgia. Maria Lourdes Motter tornou-se uma das mais respeitadas pesquisadoras de telenovela no Brasil, sendo uma das fundadoras do Núcleo de Telenovelas da Escola de Comunicações e Artes da USP.

\section{ATIVIDADES EM SALA DE AULA}

Ruth Ribas Itacarambi propõe projetos pedagógicos a serem desenvolvidos em sala de aula com alunos do ensino fundamental e médio, utilizando-se dos artigos publicados neste número.

Resumo: O tema da diversidade cultural vem sendo objeto de discussão em diversos âmbitos da vida social. Os meios de comunicação e a escola surgem, particularmente, como espaços marcados por esse debate, quer no sentido de posicioná-lo, estimulá-lo, quer para, simplesmente, esquecê-lo, discriminá-lo. De qualquer modo, um dos vetores sob os quais o problema costuma ser formulado é o dos arranjos discursivos: livros didáticos, programas de televisão, emissões de rádio etc. $\mathrm{O}$ objetivo deste artigo é discutir como determinadas tensões culturais podem ser lidas nas linguagens que circundam as mídias e a escola.

Palavras-chave: comunicação, educação, diversidade, linguagem, mídia.
Abstract: The issue of cultural diversity has been object of discussion in several aspects of social life. This debate takes shelter especially under media and school, whether in the sense of positioning and stimulating diversity or forgetting and putting it apart. In any of these senses, one of the vectors under which that issue uses to be formulated is the one of discursive arrangements: textbooks, television and radio programs, etc. This article's objective is to discuss how certain cultural tensions can be read in the languages around media and school.

Keywords: communication, education, diversity, language, media. 